\title{
Replicating Bulk Electrochemistry in Liquid Cell Microscopy
}

Khim Karki ${ }^{1}$, Tyler Mefford ${ }^{2}$, Daan Hein Alsem ${ }^{1}$, Norman Salmon ${ }^{1}$, and William C. Chueh ${ }^{2}$.

1. Hummingbird Scientific, Lacey, WA, USA.

2. Department of Materials Science and Engineering, Stanford University, Stanford, CA, USA.

Liquid electroanalytical measurements performed inside the transmission electron microscopy (TEM) and X-ray microscopy (XRM) are becoming more common and are used to study a wide range of electrochemical reaction-systems at the nanoscale [1-3]. This approach has already started to produce new insights on the dynamics and structural changes during processes as lithium ion insertion/extraction, metal nucleation during electrodeposition, dendrite formation, and metal corrosion.

Despite the power of this approach, the challenges associated with replicating bulk-scale electrochemistry data in the environmental cell microscopy platform are well-known [3, 4]. First, the hardware components are not best optimized to perform in the reduced scale environment of the TEM/XRM [5]. Second, the effect of electron (e-) beam irradiation can complicate the readings of the electrochemical data in liquid TEM [2]. Here, we present an operando liquid cell TEM/XRM microscopy platform with newly developed methodologies to mimic baseline electrochemistry using some model compounds.

The liquid cell platform used to measure and quantify electrochemical data is shown in Figure 1A. The studies are performed using electrochemical cells, which consist of two microfabricated chips sandwiched with electron transparent SiNx membranes for viewing in TEM. Using a new developed hardware system and optimized electrochemistry chips with a specialized configuration of working electrode (WE), counter electrode (CE) and reference electrode (RE), we performed cyclic voltammetry studies in 01.M CuSO4 and $20 \mathrm{mM} \mathrm{K}_{3} \mathrm{Fe}(\mathrm{CN})_{6} / 20 \mathrm{mM} \mathrm{K}_{4} \mathrm{Fe}(\mathrm{CN})_{6}$ in $0.1 \mathrm{M} \mathrm{KCl}$ solutions. In the former case (Figure 1B), the copper deposition and stripping occurs at the Pt working electrode at distinct redox peaks and the result mimics the bulk electrochemical cells with large electrode areas and larger volume of electrolyte solution [6]. In the latter case (Figures 1C and 1D), the redox reaction of $20 \mathrm{mM}$ ferrocyanide/ $20 \mathrm{mM}$ ferricyanide in $0.1 \mathrm{M} \mathrm{KCl}$ at different voltage scans show reversible electrode reaction during both the forward and reverse scans, elucidating bulk behavior [7]. This work highlights the potential sources of electrochemical measurement artefacts in liquid TEM and proposes recommendations to minimize them. For example, the measurement offsets can be based on the size and the configuration of the electrodes with respect to electrolyte coupled with the e-beam conditions. These results and methodologies demonstrate that minimizing artefacts as well optimizing the hardware for small volume and limited diffusion cell geometries allow mimicking the bulk data, which can be further implemented in the quantitative measurements of broader electrochemical systems [8].

\section{References:}

[1] M.L. Taheri et al, Ultramicroscopy 170 (2016), p. 86.

[2] F.M. Ross in "Liquid Cell Electron Microscopy", Cambridge University Press (2016).

[3] J. Lim et al, Science 353 (2016), p. 566.

[4] N. Hodnik et al, Acc. Chem. Res. 49 (2016), p. 2015.

[5] E. Fahrenkrug et al, Journal of Electrochemical Society 164 (2017), p. H358. 
[6] D. Grujicic and B. Pesic, Electrochimica Acta 47 (2002), p. 2901.

[7] N. Frenzel, J. Hartley, and G. Frisch, Phys. Chem. Chem. Phys., 19 (2017), p. 28841.

[8] KK, DHA, and NS acknowledge funding from the Department of Energy, Office of Basic Energy Sciences, SBIR Grant \# DE-SC0009573.

A

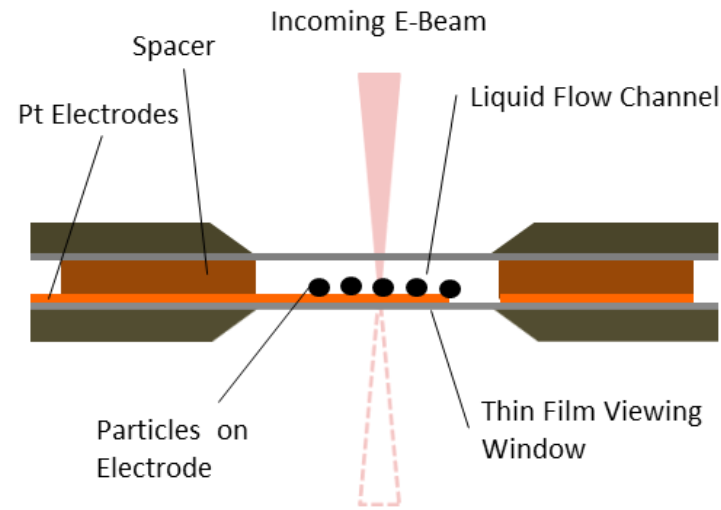

C

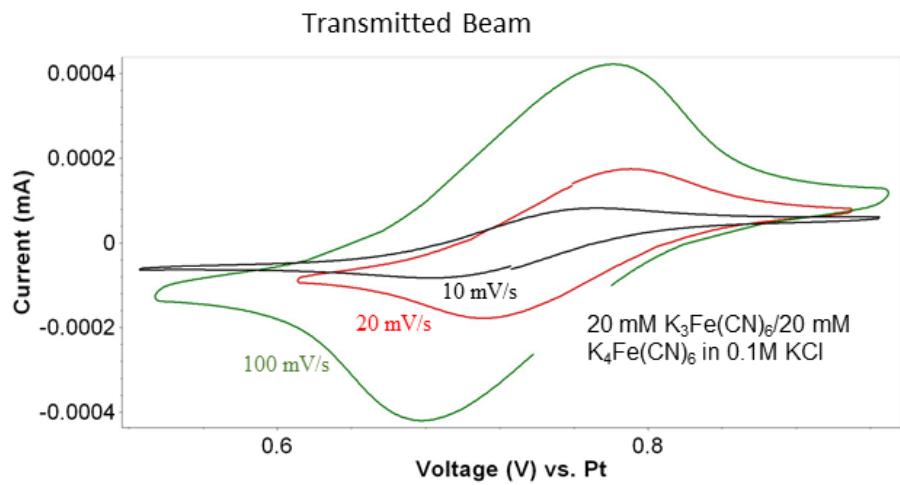

B

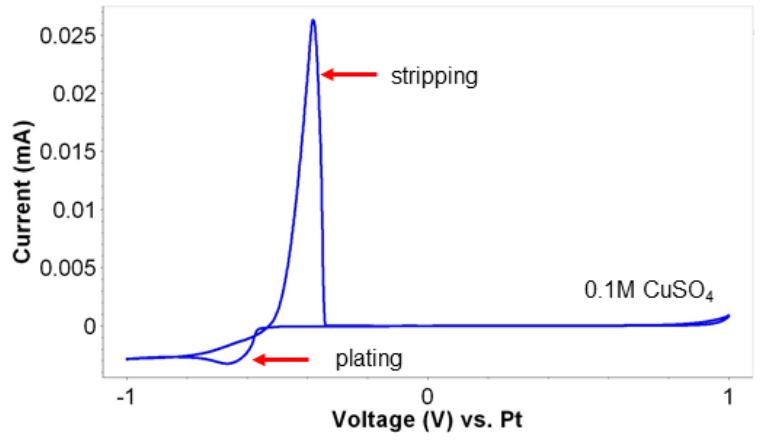

D

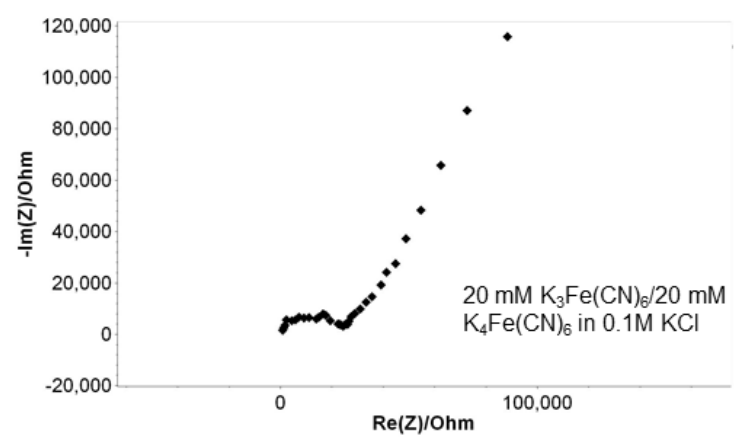

Figure 1. (A) Schematic of assembled liquid cell. (B) Cyclic voltammogram of (A) $0.1 \mathrm{M} \mathrm{CuSO}_{4}$ at 20 $\mathrm{mV} / \mathrm{s}$. (B) Cyclic voltammogram of $20 \mathrm{mM} \mathrm{K} 3 \mathrm{Fe}(\mathrm{CN})_{6} / 20 \mathrm{mM} \mathrm{K}_{4} \mathrm{Fe}(\mathrm{CN})_{6}$ in $0.1 \mathrm{M} \mathrm{KCl}$ at $10 \mathrm{mV} / \mathrm{s}, 20$ $\mathrm{mV} / \mathrm{s}$ and $100 \mathrm{mV} / \mathrm{s}$. (D) Electrochemical impedance spectroscopy of $20 \mathrm{mM} \mathrm{K} 3 \mathrm{Fe}(\mathrm{CN})_{6} / 20 \mathrm{mM}$ $\mathrm{K}_{4} \mathrm{Fe}(\mathrm{CN})_{6}$ in $0.1 \mathrm{M} \mathrm{KCl}$. 